\title{
Study on heat transfer enhancement of finned tube boiling in water tank
}

\author{
Yapeng Duan ${ }^{1}$, Xuesheng Wang ${ }^{1 *}$ \\ ${ }^{1}$ East China University of Science and Technology, Shanghai, 200000, China
}

\begin{abstract}
A passive residual heat removal heat exchanger (PRHR HX) was used as the research object, and an experimental device with heat conduction oil as the heat source was set up to complete the experimental study of the outside tube saturation boiling. The improved Wilson diagram method was used to calculate the experimental data, and the heat transfer law of the outside tube boiling of smooth tube and finned tube was obtained. Compared with the two types of tubes, the intensification rate of smooth tube was 1.07 , and that of finned tube was 2.39, and the finned tube was 2.23 times that of smooth tube. According to the intensification rate, the $\mathrm{Nu}$ modification of the heat transfer coefficient of the two tubes was further obtained.
\end{abstract}

\section{Introduction}

Atomic energy is a kind of safe, clean and economical new energy. At present, China has the demand of sustainable development of energy strategy. Atomic energy is expected to replace traditional oil, coal and natural gas in a certain range. Since the world's first nuclear power plant was built in 1954, atomic energy has played an important role in the development of world energy [1]. Atomic energy is a clean energy source, but it is also extremely dangerous. In the event of an accident such as a leak, it will cause pollution in the area of the accident that cannot be recovered. Therefore, for the development of atomic energy, safety is the first priority. After experiencing the lessons of nuclear energy development and accidents, some scholars put forward a new safety design concept, that is, immobile safety design concept. Passive safety design is to ensure the safety of the site by removing excess heat through physical laws such as gravity, evaporation, and natural circulation, which cannot be destroyed. Therefore, the corresponding safety countermeasures can be automatically completed after an accident, independent of the operational capability of the operator and the energy supply outside the system. The concept of passive safety design only relies on the natural physical laws that represent the development trend of atomic energy safety.

Yanzhen Ming, Wei Liu et al [2]. took the waste heat discharge heat exchanger of a ship as the research object and carried out numerical simulation with CFD software, which has theoretical reference significance for the design of this type of heat exchanger. Yang Song et al [3]. took PRHR HX in AP1000 as the research object and established a full-scale model with CFD software to simulate and analyze the flow and heat transfer characteristics of natural convection. The distribution of temperature field and flow field in the upper water tank and in the center tube bundle is calculated by establishing the calculation model of the connection between inside and outside the tube. Rushi Fu, Yong Li et al $[4,5]$. took different types of smooth tubes, ribbed tubes and wire-wound tubes as the research objects, compared and analyzed the process of boiling heat transfer outside tubes of various tubes by means of experiments. It is found that the boiling heat transfer coefficient can be improved to a certain extent by the two reinforced tubes.

At present, there are many researches on special heat exchange tubes in passive waste heat removal system, but few researches on slotted low-finned tubes. In this paper, smooth tube and finned tube were used as the research objects, and an experimental device for passive residual heat removal was set up with heat conduction oil as the heat source. The heat transfer of the saturated boiling outside the tube of the two tube types was studied. The improved Wilson diagram method was used to calculate the experimental data, and then the enhancement rates of the two tube types were compared. It has a certain reference significance in the design of finned tube heat exchange.

\section{Experimental equipment}

In order to simulate the operating conditions of PRHR $\mathrm{HX}$, the design process of this experiment refers to its design.

\subsection{The experimental system}

As shown in Figure 1, the experiment system of electric heating set by electricity to generate heat, until the oil

\footnotetext{
${ }^{a}$ Corresponding author: wangxs@ecust.edu.cn
} 
temperature reaches set temperature of the heating tank, remains constant, at this time because the larger temperature difference between the heating tank and water tank, the interaction between the tube heat conduction oil by temperature difference and flow, transfer heat to the water in the tank, and then through the closed loop pipe flow back to the heating tank, so it forms circulation heat transfer process. The oil pump device was added in the experiment to provide additional driving force for the experiment when the natural convection driving force was weak and the complete circulating flow could not be realized.

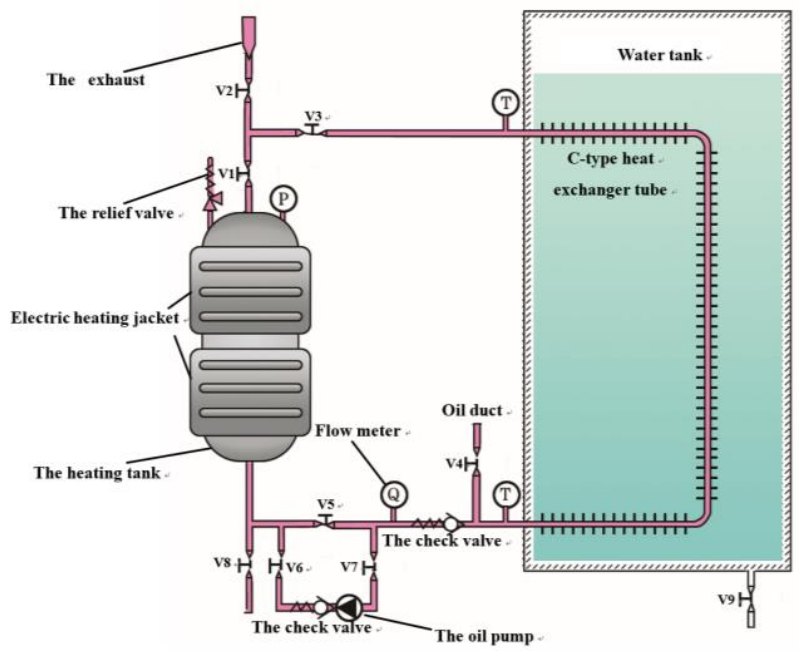

Figure 1. Flow chart of experimental equipment.

The experimental equipment mainly includes: (1) heating system; (2) experimental system; (3) Data acquisition system. The heating system, including electric heating sleeve, heating tank and some accessories, is the power source of the whole experiment; The experimental system includes a C-type heat exchange tube and a water tank, which is used to simulate the operation of PRHR HX and is the most critical part of the experiment. Data acquisition system needs to collect data including: heat exchange pipe fluid inlet and outlet and internal temperature, water temperature in the water tank, and the heat exchange pipe outer wall temperature, heating tank temperature, heat exchange pipe inlet and outlet pressure, the flow rate in the pipe. The temperature at the inlet of the $\mathrm{C}$ type heat exchanger tube is controlled by adjusting the temperature in the heating tank.

\subsection{Introduction of the experimental heat exchange tube}

Two types of heat exchange tubes, smooth tube and finned tube, are compared and analyzed. Both tubes are machined from 304C for excellent corrosion resistance. The length of the upper and lower horizontal sections is $400 \mathrm{~mm}$, and the length of the vertical sections is $1200 \mathrm{~mm}$. The technical parameters of smooth tubes and finned tubes are shown in Table 1 and Table 2.
Table 1. Technical parameters of smooth tube.

\begin{tabular}{|c|c|c|}
\hline Material & $\begin{array}{c}\text { Size } \\
(\mathrm{mm})\end{array}$ & $\begin{array}{c}\text { Yield strength } \\
(\mathrm{MPa})\end{array}$ \\
\hline $304 \mathrm{C}$ & $\Phi 19 \times 2$ & 207 \\
\hline $\begin{array}{c}\text { Elongation } \\
(\%)\end{array}$ & $\begin{array}{c}\text { Specific heat } \\
\left(\mathrm{J} / \mathrm{kg} \cdot{ }^{\circ} \mathrm{C}\right)\end{array}$ & $\begin{array}{c}\text { Density } \\
(\mathrm{g} / \mathrm{cm} 3)\end{array}$ \\
\hline 45 & 500 & 7.93 \\
\hline
\end{tabular}

Table 2. Technical parameters of finned tube.

\begin{tabular}{|c|c|c|}
\hline Material & $\begin{array}{c}\text { Size } \\
(\mathrm{mm})\end{array}$ & $\begin{array}{c}\text { Tooth depth } \\
(\mathrm{mm})\end{array}$ \\
\hline $304 \mathrm{C}$ & $\Phi 19 \times 2$ & 0.7 \\
\hline $\begin{array}{c}\text { Helix angle } \\
\left({ }^{\circ}\right)\end{array}$ & $\begin{array}{c}\text { Microgroove size } \\
(\mathrm{mm})\end{array}$ & $\begin{array}{c}\text { Microgroove } \\
\text { inclination Angle } \\
\left({ }^{\circ}\right)\end{array}$ \\
\hline 0.64 & $0.5 \times 0.5$ & 30 \\
\hline
\end{tabular}

\subsubsection{Smooth tube}

A heat exchange tube with a smooth surface is called a smooth tube. According to the size of the heat exchange tube, the heat exchange area of the tube can be calculated.

The heat exchange area in the tube is:

$$
A_{i}=\pi \cdot d_{1} L=0.059 \mathrm{~m}^{2}
$$

The external heat exchange area of the tube is:

$$
A_{o}=\pi \cdot d_{2} L=0.077 \mathrm{~m}^{2}
$$

\subsection{2. finned tube}

The finned tube used in the experiment had many "granular grooves" arranged in a spiral pattern at an Angle of $30^{\circ}$ at the equidistance of the fin. Its physical image and partial enlarged view are shown in Figure 2.

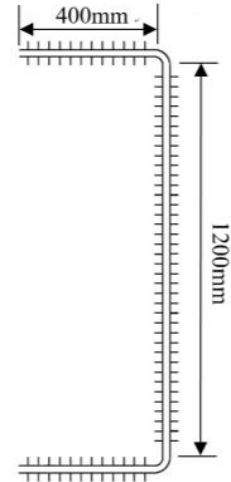

(a)

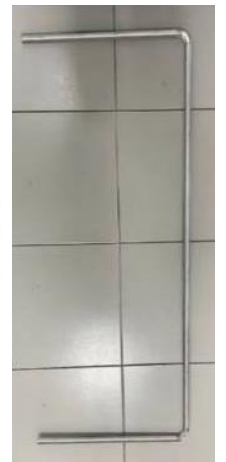

(b)

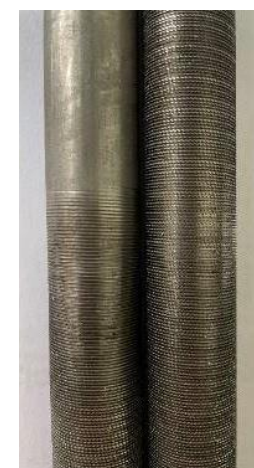

(c)
Figure 2. The C-type finned tube: (a)Schematic diagram, (b)Physical drawing, (c)Local enlargement of C-type finned tube.

Structurally, these "granular grooves" can increase the heat transfer area of the heat exchange tube without increasing the space occupied by the tube, increasing the heat flux. In addition, the "granular groove" makes the fluid outside the tube a higher flow rate, which can strengthen the disturbance, destroy the formation and development of the liquid film boundary layer outside the tube, and strengthen the heat transfer effect. The outer diameter of the base tube of the finned tube is 19 
$\mathrm{mm}$, and the inner diameter is $15 \mathrm{~mm}$. The fins are arranged in a spiral shape on the outer side of the tube, the fin spacing is $0.6 \mathrm{~mm}$, and 80 grooves are made around a circle.

The inside heat exchange area of the tube is:

$$
A_{i}=\pi \cdot d_{1} L=0.059 \mathrm{~m}^{2}
$$

The external heat exchange area of the tube is:

$$
\begin{aligned}
& A_{o}=\pi \cdot d_{2} L+2 n \cdot \pi\left[\left(\frac{d_{2}}{2}+H_{f}\right)^{2}-\left(\frac{d_{2}}{2}\right)^{2}\right]+ \\
& 2 n \cdot \frac{\pi \cdot d_{2}}{\tan \alpha \cdot 1.5} \cdot A_{m}=0.276 \mathrm{~m}^{2}
\end{aligned}
$$

The comparison between the two types of tubes shows that the external heat transfer area of the finned tube is 3.58 times that of the smooth tube.

\section{Original Wilson's graphic method}

Wilson's graphic method was first used by Wilson in 1915 to calculate the heat transfer coefficient outside the heat exchange tube [6]. It is a theoretical solution based on a large amount of data and has been adopted and improved by many scholars.

The principle of the original Wilson diagram method is based on the thermal resistance in the heat exchange tube. The total thermal resistance $R_{a}$ of the heat exchange tube is divided into the external thermal resistance $R_{o}$, the internal thermal resistance $R_{i}$, the fouling thermal resistance $R_{f}$ on the inside and outside surface of the heat exchange tube and the thermal resistance $R_{w}$ on the wall of the heat exchange tube [7]. Because the heat exchange tube needs to be cleaned and descaled, the fouling thermal resistance $R_{f}$ is ignored in the calculation. The thermal resistance formula is:

$$
R_{a}=R_{o}+R_{i}+R_{w}
$$

According to the basic theory of heat transfer, the above equation can also be changed:

$$
R_{a}=\frac{1}{h_{i}}+\frac{1}{h_{o}}+R_{w}
$$

Where $R_{w}$ is the thermal resistance of the wall of the heat exchange tube, $\left(\mathrm{m}^{2} \cdot{ }^{\circ} \mathrm{C}\right) / \mathrm{W} ; h_{i}$ is the heat transfer coefficient of the fluid inside the tube, $\mathrm{W} /\left(\mathrm{m}^{2} \cdot{ }^{\circ} \mathrm{C}\right) ; h_{o}$ is the heat transfer coefficient of the fluid outside the tube, $\mathrm{W} /\left(\mathrm{m}^{2} \cdot{ }^{\circ} \mathrm{C}\right)$.

During the experiment, the fluid flow outside the tube keep constant, there is:

$$
\frac{1}{h_{o}}+R_{w}=C_{1}
$$

Where $C_{1}$ is the undetermined constant.

According to Wilson's graphic method, when the fluid in the heat exchange tube is in turbulent state, its flow state and pipe diameter can be expressed by a parameter, namely, the velocity $u$ inside the tube. The $u$ value of flow velocity has a significant influence on the heat transfer coefficient of the inner surface of the tube, which changes proportionally and has the following relationship:

$$
h_{i}=C_{2} u^{n}
$$

Where $C_{2}$ is the undetermined constant; $u$ is the velocity of the fluid in the heat exchange tube, $\mathrm{m} / \mathrm{s} ; n$ is the velocity index.

According to the formula, the thermal resistance in the heat exchange pipe is proportional to $1 / u^{n}$. Substituting Equations (3) and (4) into Equation (2):

$$
R_{a}=\frac{1}{C_{2}} \cdot \frac{1}{u^{n}}+C_{1}
$$

It can be seen from Equation (5) that $R_{a}$ is proportional to $1 / u^{n}$. At the same time, the total heat transfer resistance $R_{a}$ can be calculated through the heat balance analysis of the whole device, that is:

$$
R_{a}=\frac{L M T D}{C_{p} q_{m} \Delta t}
$$

Where $L M T D$ is the logarithmic average temperature difference, ${ }^{\circ} \mathrm{C} ; C_{p}$ is the specific heat capacity of the fluid in the tube, $\mathrm{J} /\left(\mathrm{kg} \cdot{ }^{\circ} \mathrm{C}\right) ; q_{m}$ is the fluid traffic in the tube, $\mathrm{kg} / \mathrm{s} ; \Delta t$ is the temperature difference between inlet and outlet of the fluid, ${ }^{\circ} \mathrm{C}$.

The above parameters can be measured experimentally, so the value of $R_{a}$ can be calculated according to Equation (6).

By adjusting the flow of the fluid, that is, by changing the velocity $u$, each velocity $u$ corresponds to the total heat transfer resistance $R_{a}$, and the linear relationship between the flow velocity and the heat resistance meets the Equation (5). Taking $R_{a}$ as ordinate and $1 / u^{n}$ as abscissa, the relation graph of $1 / u^{n}-R_{a}$ is obtained, as shown in Figure 3.

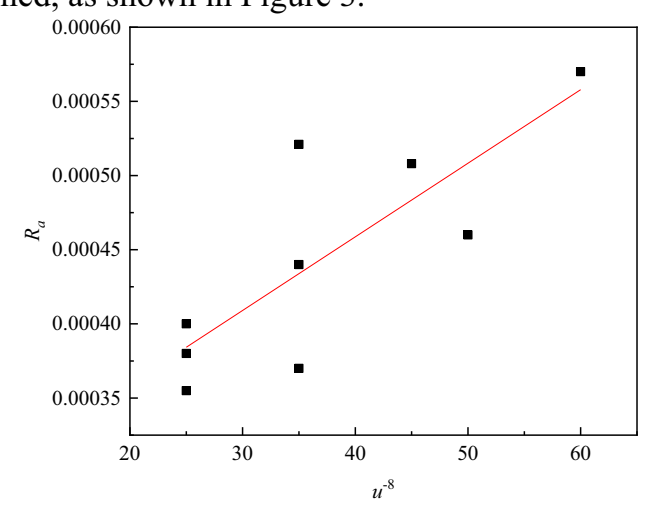

Figure 3. Results of smooth tube under Wilson graphic method.

The correlation expression of $1 / u^{n}-R_{a}$ can be obtained by experimental data fitting:

$$
R_{a}=4.30 \times 10^{-6} \frac{1}{u^{0.8}}+2.79 \times 10^{-4}
$$

Therefore, the in-pipe heat transfer coefficient of a smooth pipe can be expressed by Equation (4) as: 


$$
h_{i}=2.33 \times 10^{5} \cdot u^{-0.8}
$$

\section{Improved Wilson's graphical method}

There are two assumptions about Wilson's graphical method: (1) The thermal resistance of the fluid on one side does not change with time; (2) The heat transfer coefficient of the fluid on the other side has a fixed function relationship with the flow velocity.

Based on the two points, many scholars have made more accurate calculations for Wilson's graphic method. Its general expression is:

$$
N u=C R e^{n} \operatorname{Pr}^{m}
$$

Where $N u$ is the Nussel number; $C$ is the undetermined constant; $R e$ is Reynolds number; $\operatorname{Pr}$ is the Prandtl number.

The above equation can explain the relationship between heat transfer and velocity of fluid inside and outside the tube. In addition, in order to find a more general relationship, some scholars began to study the two-phase heat transfer with phase transition. The general expression can be expressed as:

$$
h=C f[m(u), X, \cdots]
$$

Where $h$ is the heat transfer coefficient, $\mathrm{W} /\left(\mathrm{m}^{2} \cdot{ }^{\circ} \mathrm{C}\right)$; $m(u)$ is the fluid flow rate, $\mathrm{kg} / \mathrm{s} ; X$ is the dryness of the inlet fluid.

The total heat transfer resistance can be expressed as:

$$
R_{a}=\frac{1}{C f[m(u), X, \cdots] A}+R_{w}+R_{B}
$$

The above equation is fitted as shown in Figure 4. Calculate the slope of the graph, and its inverse is the value of $C$

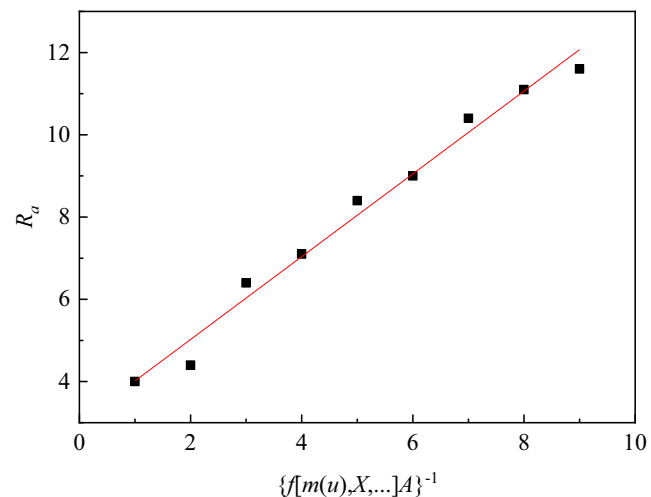

Figure 4. Improved Wilson graphic method fitting diagram.

Compared with the original Wilson graphic method, the improved method has better adaptability and more accurate calculation results. It should be noted that this method has its limitations, such as having to conform to the above two assumptions. Because the experiment working condition applicable to this method, it will not be discussed.

\section{Experimental regression correlation}

The relation of thermal resistance of each part is as follows:

$$
\frac{1}{K}=\frac{1}{h_{o}}+R_{f}+\frac{1}{h_{i}}+R_{w}
$$

The above equation can be written as:

$$
\frac{1}{K A_{i}}-R_{w}=\frac{1}{h_{o} A_{o}}+\frac{1}{h_{i} A_{i}}
$$

Where $K$ is the total heat transfer coefficient, $\mathrm{W} /\left(\mathrm{m}^{2}{ }^{\circ} \mathrm{C}\right) ; A_{i}$ is the heat transfer area inside the tube, $\mathrm{m}^{2}$ $A_{o}$ is the heat transfer area outside the tube, $\mathrm{m}^{2}$.

$h_{o}$ is separated from Equation (13) by Wilson's graphic method. The specific method is as follow:

The heat transfer coefficient inside the pipe can be solved by Dittus-Boelter empirical formula, that is:

$$
h_{i}=C_{i} \cdot 0.023 \operatorname{Re}^{0.8} \operatorname{Pr}^{0.4}
$$

Where $C_{i}$ is the intensification rate inside the heat exchange tube.

The above equation can be written as:

$$
h_{i}=C_{i} \cdot 0.023\left(\frac{\rho u D}{\mu}\right)_{i}^{0.8}\left(\frac{C_{p} \mu}{\lambda}\right)_{i}^{0.4}
$$

Where $\rho$ is density, $\mathrm{kg} / \mathrm{m}^{3} ; D$ is the diameter of the heat exchange tube, $\mathrm{m} ; \mu$ is dynamic viscosity, $\mathrm{kg} /(\mathrm{m} \cdot \mathrm{s})$; $C_{p}$ is the specific heat capacity at constant pressure, $\mathrm{J} /\left(\mathrm{kg} \cdot{ }^{\circ} \mathrm{C}\right) ; \lambda$ is the fluid thermal conductivity, $\mathrm{W} /\left(\mathrm{m} \cdot{ }^{\circ} \mathrm{C}\right)$.

The heat transfer coefficient of the fluid outside the tube can be obtained according to the correlation formula of Nusselt experiment:

$$
h_{o}=2.44\left[\frac{\lambda_{o}^{3} \rho_{o}^{2} g h_{f g}}{\mu_{o} L\left(T_{s}-T_{w}\right)}\right]^{1 / 4}
$$

Where $T_{s}-T_{w}=\frac{Q}{A_{o} h_{o}}, Q$ is the heat flux, W. Substituting into the above equation:

$$
h_{o}=\left(C_{o}\right)^{4 / 3} \cdot 0.925\left[\frac{\lambda_{o}^{3} \rho_{o}^{2} g h_{f g}}{\mu_{o} L\left(Q / A_{o}\right)}\right]^{1 / 3}
$$

Where $C_{o}$ is the strengthening ratio outside the heat exchange tube.

Substituting Equations (15) and (17) into Equation (13): 


$$
\begin{aligned}
& \frac{1}{K A_{i}}-R_{w}=\frac{1}{\left(C_{o}\right)^{4 / 3} \cdot 0.925\left[\frac{\lambda_{o}^{3} \rho_{o}^{2} g h_{f g}}{\mu_{o} L\left(\frac{Q}{A_{o}}\right)}\right]^{1 / 3} A_{o}} \\
& +\frac{1}{C_{i} \cdot 0.023\left(\frac{\rho u D}{\mu}\right)_{i}^{0.8}\left(\frac{C_{p} \mu}{\lambda}\right)_{i}^{0.4} A_{i}}
\end{aligned}
$$

Both sides of the equation(18) multiply the $0.023\left(\frac{\rho u D}{\mu}\right)_{i}^{0.8}\left(\frac{C_{p} \mu}{\lambda}\right)_{i}^{0.4} A_{i}$ to get:

$$
\begin{aligned}
& \left(\frac{1}{K A_{i}}-R_{w}\right)\left[0.023\left(\frac{\rho u D}{\mu}\right)_{i}^{0.8}\left(\frac{C_{p} \mu}{\lambda}\right)_{i}^{0.4} A_{i}\right] \\
& =\frac{0.023\left(\frac{\rho u D}{\mu}\right)_{i}^{0.8}\left(\frac{C_{p} \mu}{\lambda}\right)_{i}^{0.4} A_{i}}{\left.C_{o}\right)^{\frac{1}{3}} \cdot 0.925\left[\frac{\lambda_{o}^{3} \rho_{o}^{2} g h_{f g}}{\mu_{o} L\left(\frac{Q}{A_{o}}\right)}\right]^{\frac{1}{3}} A_{o}}
\end{aligned}
$$

$$
\begin{gathered}
\text { Make: } a=\left(C_{o}\right)^{-4 / 3}, b=\frac{1}{C_{i}}, \\
0.023\left(\frac{\rho u D}{\mu}\right)_{i}^{0.8}\left(\frac{C_{p} \mu}{\lambda}\right)_{i}^{0.4} A_{i} \\
{\left[\frac{\lambda_{o}^{3} \rho_{o}^{2} g h_{f g}}{\mu_{o} L\left(\frac{Q}{A_{o}}\right)}\right]^{\frac{1}{3}} A_{o}}
\end{gathered}
$$

$y=\left(\frac{1}{K A_{i}}-R_{w}\right)\left[0.023\left(\frac{\rho u D}{\mu}\right)_{i}^{0.8}\left(\frac{C_{p} \mu}{\lambda}\right)_{i}^{0.4} A_{i}\right]$, Then

Equation (19) can be expressed as:

$$
y=a x+b
$$

Refer to the material properties of the two heat exchange tubes, and combine with their structural parameters, take the experimental data as the values of $x$ and $y$, select a number of groups of $(x, y)$ data and represent a number of points in the coordinate system. Through formula regression, the regression formula between $y$ and $x$ is obtained, as shown in Figure 5.The geometrical properties in the figure have special mathematical significance, with slope $a$ representing $\left(C_{o}\right)^{-4 / 3}$ and intercept $b$ representing $1 / C_{i}$. Find the slope and the intercept of the line, and get the values of $C_{o}$ and $C_{i}$. Substituting the obtained $C_{o}$ and $C_{i}$ into Equations
(15) and (17) respectively, the regression correlation formula for the heat transfer coefficients $h_{o}$ and $h_{i}$ can be obtained.

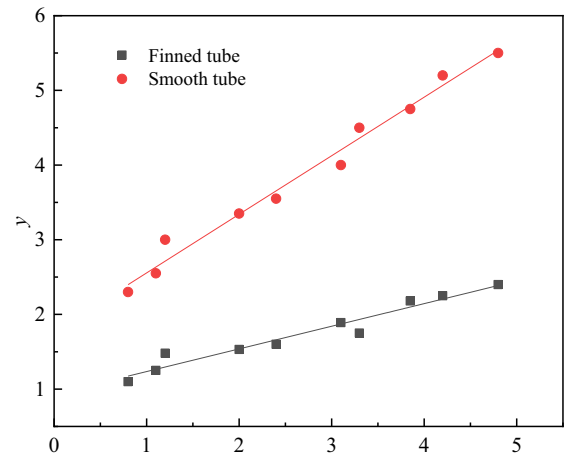

Figure 5. Results of improved Wilson graphic method for two tubes.

By observing Figure 5, it can be found that the points calculated by the improved Wilson graphical method have better linear regression. By observing the two lines in the figure, the slope of the smooth pipe $a_{1}=0.78$ and the intercept $b_{1}=1.77$, finned tube slope $a_{2}=0.3$ and intercept $b_{2}=0.93$. Substituting them into Equation (20), the fitting formulas of the two pipes can be obtained as follows:

For smooth tubes:

$$
y=0.78 x+1.77
$$

For finned tubes:

$$
y=0.3 x+0.93
$$

According to the above method, the values of intensification rate $C_{i}$ and $C_{o}$ were obtained, and the results were shown in Table 3.

Table 3. The results of improved Wilson graphic method.

\begin{tabular}{|c|c|c|}
\hline Tube type & $C_{o}$ & $C_{i}$ \\
\hline Smooth tube & 1.07 & 0.89 \\
\hline Finned tube & 2.39 & 1.05 \\
\hline
\end{tabular}

The smooth tube intensification rate outside the tube was 1.07 , the intensification rate inside the tube was 0.89 . The finned tube intensification rate inside the tube was 1.05. The difference between them and 1 was the theoretical calculation error, which were $0.07,0.11$ and 0.05 respectively, within the acceptable range. Therefore, it can be inferred that the calculated intensification rate outside the tube of finned tube is also reliable. The $C_{o}$ of the finned tube is 2.39 , which is 2.23 times of that of the smooth tube.

Substituting the calculated $C_{o}$ into Equation (17), the $\mathrm{Nu}$ modification formula for calculating the heat transfer coefficient outside the tube can be obtained. The formula of two pipes are shown as follows:

For smooth tubes:

$$
h_{o}=1.07\left[\frac{\lambda_{o}^{3} \rho_{o}^{2} g h_{f g}}{\mu_{o} L\left(T_{s}-T_{w}\right)}\right]^{1 / 4}
$$

For finned tubes: 


$$
h_{o}=2.39\left[\frac{\lambda_{o}^{3} \rho_{o}^{2} g h_{f g}}{\mu_{o} L\left(T_{s}-T_{w}\right)}\right]^{1 / 4}
$$

According to the analysis of the intensification rate, the error is within the acceptable range. Therefore, the correlation formula of heat transfer coefficient calculation has practical engineering guiding significance.

\section{Conclusion}

The study takes the PRHR HX as the research object, and sets up an experimental device using heat conduction oil as the heat source. The technical parameters of smooth tube and finned tube are introduced, and the heat transfer area outside the tube of the two tubes is compared, and the experimental study of saturation boiling outside the tube is completed. The improved Wilson graphic method was used to calculate the experimental data, and the heat transfer law of the smooth tube and the finned tube and the $\mathrm{Nu}$ modification formula of the heat transfer coefficient of the two tubes were obtained. The results showed that: Smooth tube intensification rate outside the tube was 1.07, the intensification rate inside the tube was 0.89 . The finned tube intensification rate inside the tube was 1.05 . because of the smooth tube internal and external surface and finned tube internal surface are smooth, no intensification effect. So the three surface intensification rate calculated by improved Wilson's graphic method are in good agreement with the actual results. It is proved that this method can be used to calculate the intensification rate of heat exchange tubes. The intensification rate of the finned tube outside the tube is 2.39, which indicates that the finned tube has good heat transfer intensification effect.

\section{References}

1. J. Chen, L. Xia. Nuclear Power Development. J. Value Engineering, 26: 245-249 (2017)

2. H. Wang. PRHR HX. J. Nondestructive Testing, 9: 21-25 (2020)

3. Y. Song, W. Li. PRHR HX J. Atomic Energy Science and Technology, 46: 767-770 (2012)

4. R. Fu. PRHR HX. D. Harbin Engineering University. (2008)

5. Y. Li, C. Yan. Research on heat transfer characteristic of PRHR HX at initial operating stage. J. Atomic Energy Science and Technology, 8: 931936 (2011)

6. T. Muszynski, Compact Heat Exchanger. J. Experimental Thermal and Fluid Science, 99: 336343 (2018)

7. Y. Chen, X. Ning, S. Su. Heat Transfer Resistance. J. MATEC Web of Conferences, 257: 1001 (2019) 